\title{
Aplikasi Geospasial Untuk Analisis Potensi Bahaya Longsor Menggunakan Metode Weighted Overlay (Studi Kasus Kabupaten Kudus, Jawa Tengah)
}

\author{
Nurfaiz Fathurrahman Yasien ${ }^{1 *}$, Felia Yustika ${ }^{1}$, Intan Permatasari ${ }^{1}$, Muthiah Sari ${ }^{2}$ \\ ${ }^{1}$ Jurusan Teknik Geofisika, Fakultas Teknik, Universitas Lampung, Jl. Prof. Dr. Ir. Sumantri Brojonegoro, Bandar Lampung, \\ Lampung 35141 \\ ${ }^{2}$ Program Studi Teknik Geofisika, Institut Teknologi Sumatera, Jalan Terusan Ryacudu, Way Hui, Kecamatan Jati Agung, Lampung \\ Selatan 35365
}

Dikirim:
26 September 2020
Direvisi:
2 Mei 2021
Diterima:
17 Mei 2021
*Email Korespondensi:
nurfaizfy19@gmail.com
2@) (i) (2)

\begin{abstract}
Abstrak: SIG sebagai media untuk mempermudah penyajian informasi spasial juga dapat dimanfaatkan sebagai dasar interpretasi daerah potensi bencana longsor. Penelitian ini bertujuan untuk mengetahui potensi bencana tanah longsor di Kabupaten Kudus dengan menggunakan metode Weighted Overlay. Metode ini merupakan analisis spasial menggunakan teknik overlay pada beberapa peta yang berkaitan dengan faktorfaktor yang dapat mempengaruhi penilaian kerentanan dengan teknik yang menerapkan sebuah skala penilaian untuk membedakan dan menidaksamakan input menjadi sebuah analisa yang terintegrasi. Penelitian ini juga menggunakan data analisis Boolean, dengan parameter yaitu data kelerengan, data curah hujan, data jenis tanah, data tutupan lahan, data infrastruktur, dan data struktur geologi. Hasil penelitian menunjukkan bahwa potensi bencana tanah longsor di kabupaten kudus ini terbagi menjadi 4 kelas yaitu sangat rendah, rendah, tinggi dan sangat tinggi. Sedangkan wilayah-wilayah yang memiliki tingkat kerawanan longsor sebagai berikut: wilayah tingkat potensi longsor rendah adalah Kecamatan Bae, Kaliwungu, Kota Kudus, Jati Mejobo, dan Kecamatan Undaan. Dan wilayah tingkat longsor tinggi pada Kabupaten Kudus adalah sebagian Kecamatan Jekulo, Kecamatan Dewe dan Kecamatan Gebog.
\end{abstract}

Kata kunci: tanah longsor, weighted overlay, geospasial, Kabupaten Kudus

\begin{abstract}
GIS as a medium to facilitate the presentation of spatial information can also be used as a basis for the interpretation of areas with potential for landslides. This study aims to determine the potential for landslides in Kudus Regency by using the Weighted Overlay method. This method is a spatial analysis using an overlay technique on several maps related to the factors that can affect the vulnerability assessment with a technique that applies a rating scale to differentiate and disproportionate inputs into an integrated analysis. This study also uses boolean analysis data, with parameters, namely slope data, rainfall data, soil type data, land cover data, infrastructure data, and geological structure data. The results showed that the potential for landslides in this holy district was divided into four classes, namely very low, low, high, and very high. Meanwhile, areas with a low landslide hazard are as follows: areas with low landslide potential are Bae, Kaliwungu, Kota Kudus, Jati Mejobo, and Undaan Districts. And the high landslide rate areas in Kudus Regency are part of Jekulo District, Dewe District, and Gebog District.
\end{abstract}

Keywords: landslide, weighted overlay, geospatial, Kudus Regency

\section{PENDAHULUAN}

Indonesia merupakan negara yang sangat rawan akan berbagai bencana alam, seperti kekeringan, banjir, tanah longsor, letusan gunung berapi, dan bencana gempa bumi serta tsunami. Tanah longsor yang melanda berbagai wilayah di Indonesia adalah suatu fenomena alam yang terjadi dikarenakan adanya beberapa faktor. Karena sebagian wilayah di Indonesia merupakan wilayah pegunungan dan perbukitan yang rawan sekali terjadi bencana tanah longsor. Ditambah lagi negara Indonesia yang memiliki iklim tropis dan dengan curah hujan yang sangat tinggi, sehingga sering terjadi bencana longsor di beberapa daerah di Indonesia (Ramadhan dkk., 2017).

Bencana tanah longsor merupakan bencana alam yang memakan banyak korban jiwa. Ada beberapa faktor yang dapat menyebabkan terjadinya bencana tanah longsor, di antaranya seperti hujan lebat dengan waktu yang relatif lama, lereng gunung yang gundul dan kondisi tanah yang tidak stabil sehingga dapat membuat tanah-tanah ini tidak mampu menahan air di saat terjadi hujan yang sangat lebat. Akan tetapi, tanah longsor juga bisa ditimbulkan oleh aktivitas gunung berapi atau gempa (Bahrudin, 2019).

Mengingat banyaknya bencana tanah longsor di Indonesia, maka perlu dilakukan penelitian mengenai analisis bahaya longsor sebagai sarana dalam penanggulangan bencana alam. Kurangnya pengetahuan masyarakat akan adanya kemungkinan bencana yang dapat terjadi dan kurangnya sosialisasi mengenai upaya pencegahan menyebabkan tingginya tingkat kerugian yang akan diterima oleh masyarakat ketika bencana alam terjadi. Oleh karena itu, informasi awal mengenai potensi dan resiko bencana dapat menjadi salah satu media informasi yang dapat digunakan sebagai dasar tanggap bencana bagi masyarakat (Damanik \& Restu, 2012).

Penelitian ini bertujuan untuk memberikan analisis potensi bahaya bencana tanah longsor di Kabupaten Kudus, Jawa Tengah menggunakan metode Weighted Overlay yang merupakan analisis 
spasial dengan menggunakan teknik overlay beberapa peta yang berkaitan dengan faktor-faktor yang dapat mempengaruhi penilaian kerentanan dengan teknik yang menerapkan sebuah skala penilaian untuk membedakan dan menidaksamakan input menjadi sebuah analisa yang terintegrasi. Weighted Overlay memberikan pertimbangan terhadap faktor atau kriteria yang ditentukan dalam sebuah proses pemilihan kesesuaian (Sofyan dkk., 2010).

Penelitian ini dilakukan untuk mengetahui potensi bencana tanah longsor di Kabupaten Kudus menggunakan metode Weighted Overlay. Sehingga dapat memberikan informasi mengenai wilayah-wilayah di Kabupaten Kudus yang memiliki kerawanan terjadinya bencana tanah longsor yang kemudian dari hasil penelitian ini diharapkan dapat dijadikan acuan dalam melakukan upaya pencegahan. Kemudian dideskripsikan pemanfaatan SIG dalam analisis potensi bencana tanah longsor di Kabupaten Kudus.

Dengan menggabungkan data curah hujan, data struktur geologi, data kemiringan lereng, data jenis tanah, data infrastruktur, dan data tutupan lahan yang telah dioverlay sebelumnya dapat memberikan informasi dalam penanggulangan bencana alam. Berkaitan dengan Peraturan Pemerintah No. 21 tahun 2008 pasal 15, kegiatan penelitian mengenai potensi bencana tanah longsor di Kabupaten Kudus ini dimaksudkan sebagai salah satu kegiatan kesiapsiagaan agar dapat mengurangi resiko dampak yang diakibatkan oleh bencana tanah longsor terhadap masyarakat yang berada di Kabupaten Kudus.

\section{Tinjauan Pustaka}

Secara geografis Kabupaten Kudus merupakan provinsi Jawa Tengah yang terletak di antara $110^{\circ} 36^{\prime}$ dan $110^{\circ} 50^{\prime}$ BT serta $6^{\circ} 51^{\prime}$ dan $7^{\circ} 16$ LS. Secara administrasi Kabupaten Kudus dibatasi oleh sebelah Utara yaitu Kabupaten Jepara, sebelah Timur yaitu Kabupaten Pati, sebelah Selatan yaitu Kabupaten Grobogan dan Kabupaten Pati serta sebelah Barat yaitu Kabupaten Demak.

\subsection{Kondisi Geologi}

Kondisi geologi Kabupaten Kudus merupakan struktur geologi primer yang terdiri dari kenampakan perlapisan batu gamping dan pasir di bagian selatan dari Kota Kudus. Fase tektonik yang terjadi di Komplek Muria yang erat kaitannya dengan fase tektonik di cekungan Jawa Timur Utara, terutama Zona Rembang (Van Bemmelen, 1949). Zona Rembang mengalami dua kali fase tektonik, yaitu pada Kala Miosen Tengah dan Kala Plistosen Bawah.
Kabupaten Kudus memiliki struktur tanah yang bervariasi, mulai daerah pantai, perbukitan hingga pegunungan. Berikut ini adalah jenis-jenis tanah yang ada di Kabupaten Kudus dan penyebarannya:

1. Jenis tanah andosol. Jenis tanah ini tersebar di Kecamatan Dawe dan Kecamatan Gebog.

2. Jenis tanah grumosol mediteran. Jenis tanah ini tersebar di Kecamatan Jekulo, Kecamatan Gebog, dan Kecamatan Dawe.

3. Jenis tanah latosol merah. Penyebarannya meliputi Kecamatan Jekulo.

4. Jenis tanah planosol coklat. Jenis tanah ini tersebar di Kecamatan Gebog dan Kecamatan Kaliwungu.

5. Jenis tanah latosol coklat. Jenis tanah ini tersebar di Kecamatan Gebog dan Kecamatan Dawe.

6. Jenis tanah litosol grumosol. Jenis tanah ini tersebar di Kecamatan Jekulo, Kecamatan Gebog, dan Kecamatan Dawe.

7. Jenis tanah mediteran. Jenis tanah ini tersebar di Kecamatan Jekulo, Kecamatan Dawe, Kecamatan Gebog, Kecamatan Bae, Kecamatan Kota, Kecamatan Jati, Kecamatan Mejobo, dan Kecamatan Kaliwungu.

8. Jenis tanah aluvial coklat. Jenis tanah ini paling banyak dijumpai di Kecamatan Jati, Kecamatan Undaan, Kecamatan Jekulo, Kecamatan Mejobo, dan Kecamatan Kaliwungu.

Pada daerah kudus terdapat stratigrafi dibagi 4 satuan batuan tidak resmi. Urutan bersifat Primer dari yang Tua Breksi-piroklastik Muria dan Lava Muria yang memiliki umur sama Plistosen AkhirHolosen memiliki hubungan selaras menjari. Diendapkan di atasnya secara selaras bersifat sekunder Breksi-laharik Muria berumur Holosen, kemudian Endapan Aluvial berumur Holosen memiliki hubungan tidak selaras. Struktur yang berkembang di daerah telitian berupa kekar dengan arah utara timur laut - selatan barat daya. Karakteristik longsoran daerah penelitian didapatkan hasil bahwa aspek geologi yang mendominasi terjadinya longsor adalah pola pengaliran paralel, kemiringan curam, menempati satuan breksi-laharik Muria dan vegetasi penutup pohon berbatang keras dengan jenis longsor debris avalance yang dominan struktur geologi kekar sebagai pengontrol longsoran (Suryana, 2014). 


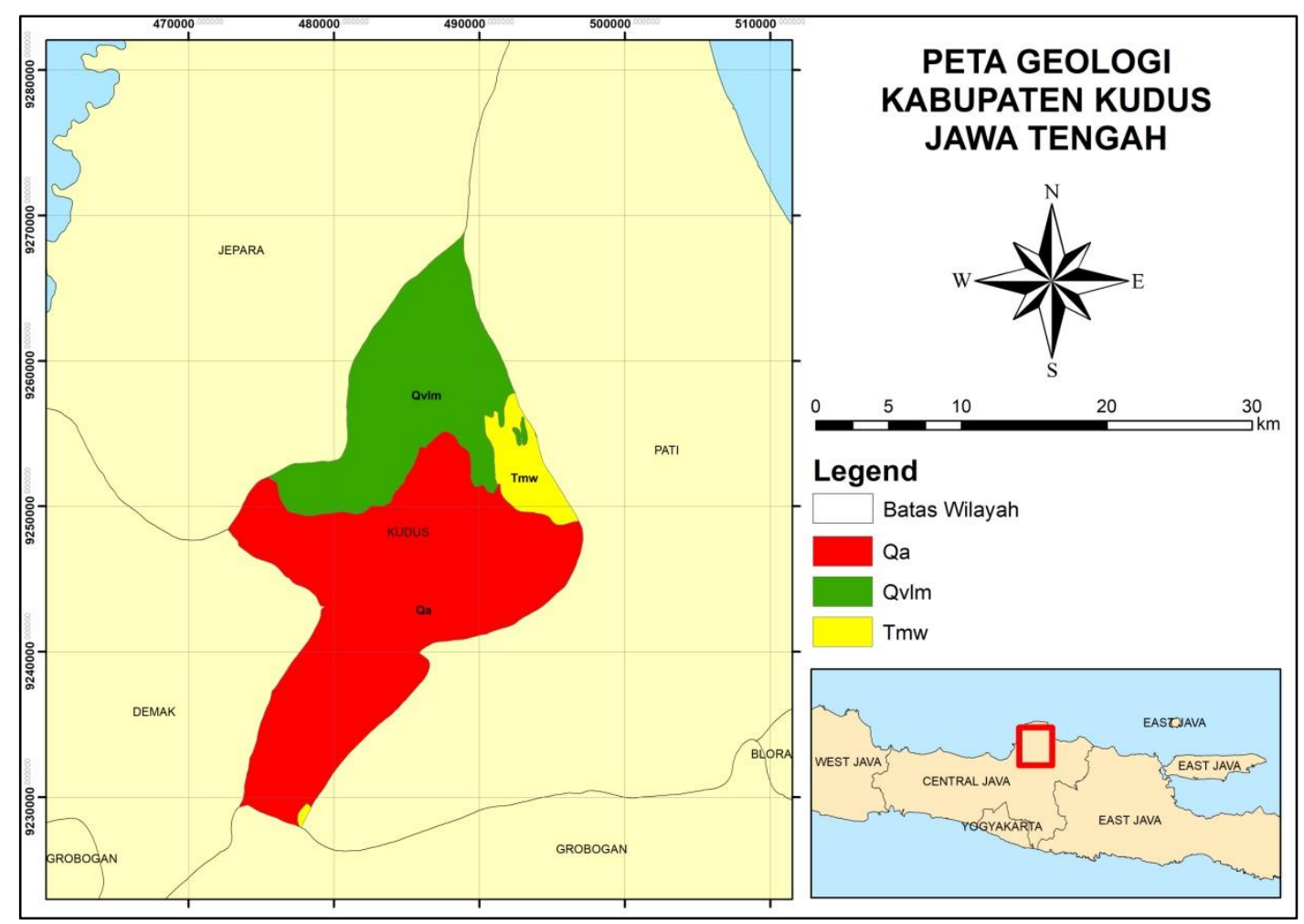

Gambar 1. Peta Geologi Kabupaten Kudus

\subsection{Longsor}

Longsor adalah proses bergeraknya massa batuan dan tanah menuruni lereng di bawah pengaruh gravitasi bumi. Tanah longsor merupakan proses alam yang banyak terjadi pada hampir di seluruh belahan bumi dan bencana ini dapat timbul disebabkan oleh dinamika kehidupan manusia seperti pembangunan yang berlebihan yang dapat menyebabkan kerusakan lingkungan atau kerugian besar pada harta benda. Penyebab terjadinya longsor banyak macamnya, faktor-faktor terjadinya longsor di antaranya adalah akibat curah hujan yang tinggi yang banyak terjadi pada daerah tropis, jenis tutupan lahan, kemiringan lereng, jenis bebatuan, dan iklim (Rezainy, 2011).

\subsection{Metode Weighted Overlay}

Metode Weighted Overlay merupakan analisis spasial dengan menggunakan teknik overlay beberapa peta yang berkaitan dengan faktor-faktor yang berpengaruh terhadap penilaian kerentanan. Alat yang digunakan dalam analisis ini adalah Geographic Information System (GIS) (Chandra \& Rima, 2013). Salah satu fungsi dari metode Weighted Overlay ini adalah untuk menyelesaikan masalah multikriteria seperti pemilihan lokasi optimal atau pemodelan kesesuaian. Metode Weighted Overlay merupakan salah satu fitur yang tersedia dalam program ArcGIS yang mengombinasikan berbagai macam input data dalam bentuk peta grid dengan pembobotan (weigted factor) dari AHP expert (Adininggar dkk., 2016).

Dalam penggunaannya, metode ini menggunakan data raster yang memiliki satuan terkecil berupa pixel sehingga dari data ini dapat dilakukan skoring dan pembobotan dari setiap pixel yang memiliki nilainya masing-masing. Overlay beberapa data raster dapat menggunakan skala pengukuran umum dan bobot masing-masing sesuai dengan kebutuhannya. Dalam penggunaan metode Weighted Overlay, semua data raster yang digunakan harus berbentuk integer.

Data raster yang masih berbentuk floating-point harus dikonversi terlebih dahulu menjadi raster bilangan bulat sebelum dapat digunakan dalam pengolahan dengan metode weighted overlay. Setiap kelas nilai dalam data raster yang diinput kemudian diberi nilai baru berdasarkan pada skala evaluasi yang digunakan. Setiap raster yang diinputkan dibobotkan menurut kebutuhannya atau digambarkan melalui persentasenya, jumlah dari persen pengaruh bobot harus 100 persen. Mengubah skala evaluasi atau pengaruh persentase dapat mengubah hasil dari analisis Weighted Overlay (Adininggar dkk., 2016).

\section{BAHAN DAN METODE PENELITIAN}

Metode yang digunakan pada penelitian ini adalah Weighted Overlay. Teknik ini menggabungkan pembobotan tiap parameter dan juga skoring pada setiap kelas parameter. Kemudian setiap parameter ditumpang-tindihkan yang akan menghasilkan peta kerawanan longsor di Kabupaten Kudus. Tahapan-tahapan dalam melaksanakan penelitian ini secara garis besar terdiri dari tahap pengumpulan data, pengolahan data, dan analisis \& kesimpulan hasil penelitian Gambar 2. Pengumpulan data yang dilakukan melalui media online yang didapatkan dari situssitus resmi, di antaranya: Indonesia Geospasial Portal, CGIAR-CSI, dan Data Online BMKG. 


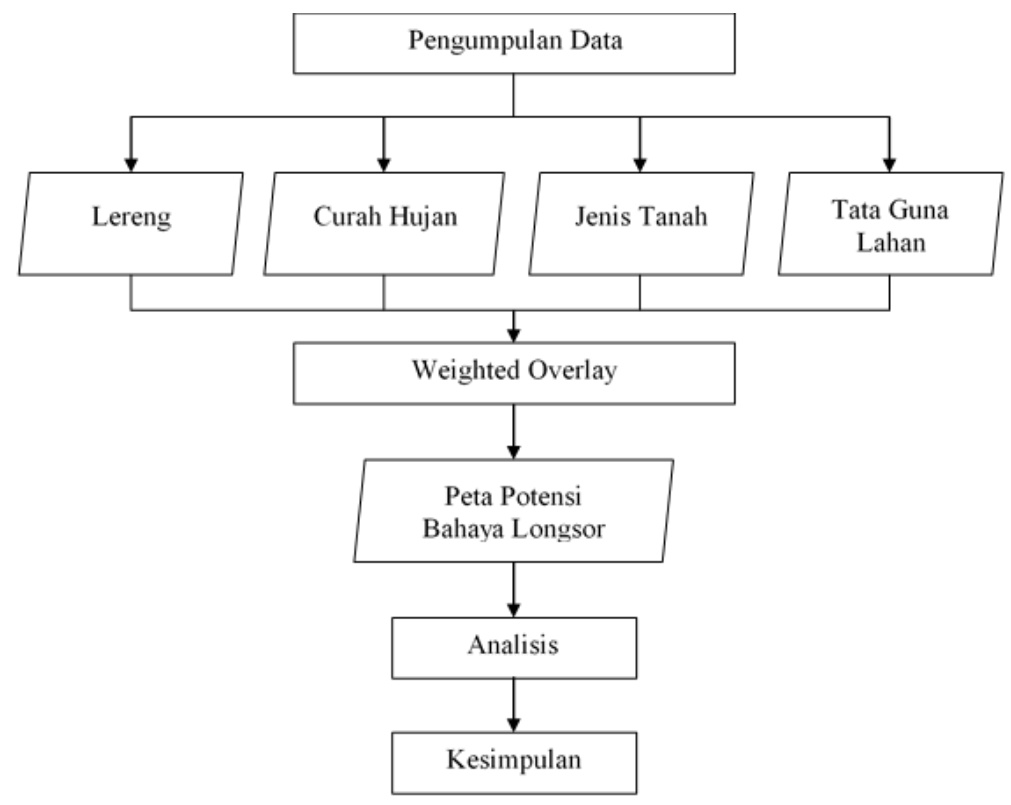

Gambar 2. Diagram Alir Penelitian

Tabel 1. Model skor dan pembobotan untuk analisis geospasial potensi longsor dengan index/Weighted Overlay KemenPU.

\begin{tabular}{lr}
\hline \multicolumn{1}{c}{ Parameter } & Bobot KemenPU \\
\hline Tutupan Lahan & $20 \%$ \\
Infrastruktur & $10 \%$ \\
Kemiringan Lereng & $25 \%$ \\
Jenis Tanah dan & $15 \%$ \\
Morfologi & \\
Struktur Geologi & $10 \%$ \\
Curah Hujan Tahunan & $20 \%$ \\
\hline
\end{tabular}

Data yang dilakukan menggunakan data analisis Boolean dengan parameter data yang terjadinya longsor, yaitu data kelerengan, data curah hujan, data jenis tanah, data tutupan lahan, data infrastruktur, dan data struktur geologi.

\subsection{Pembuatan Peta Kelerengan (Kemiringan Lereng)}

Kelerengan lahan merupakan salah satu faktor pemicu terjadinya erosi dan longsor. Biasanya longsor dapat terjadi pada kawasan dengan kelerengan curam. Oleh karena itu, faktor kelerengan selalu dimasukkan sebagai salah satu faktor utama karena semakin tinggi tingkat kecuraman lereng maka menghasilkan zona yang tingkat rawan longsor yang tinggi (Buchori \& imam, 2012).

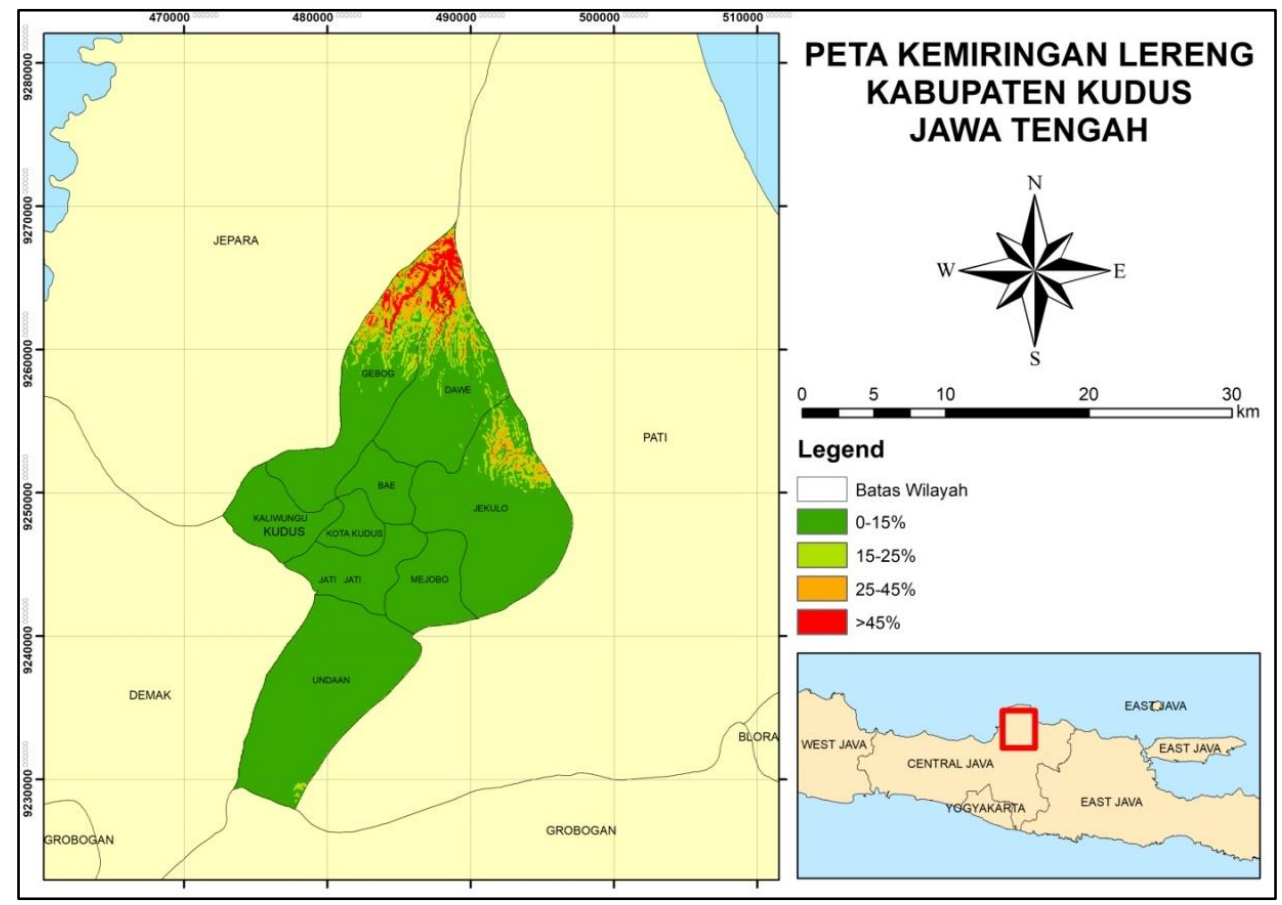

Gambar 3. Peta Kemiringan Lereng Kabupaten Kudus 
Peta kelerengan didapatkan dari proses pembuatan Slope menggunakan Citra DEM. Citra DEM yang digunakan pada penelitian ini adalah Citra DEM SRTM daerah Jawa Tengah. Karena lokasi penelitian berada di Kabupaten Kudus, langkah pertama yang dilakukan yaitu melakukan pemotongan (clip) citra DEM SRTM agar didapatkan citra DEM daerah Kabupaten Kudus. Setelah itu dilakukan proses Slope agar didapatkan peta kelerengan. Pada Gambar 3 adalah hasil dari peta kelerengan Kabupaten Kudus.

\subsection{Pembuatan Peta Curah Hujan}

Curah hujan merupakan salah satu unsur iklim yang besar perannya terhadap kejadian longsor dan erosi. Hujan dapat berpotensi menimbulkan tanah longsor apabila intensitas hujannya cukup tinggi dan dalam kurun waktu yang relatif lama. Selain itu, ukuran butir hujan juga berperan dalam menentukan longsor. Pembuatan peta curah hujan di dapat menggunakan data curah hujan daerah Kabupaten Kudus yang di dapat dari CHRS Data Portal seperti pada Gambar 4 di bawah ini.

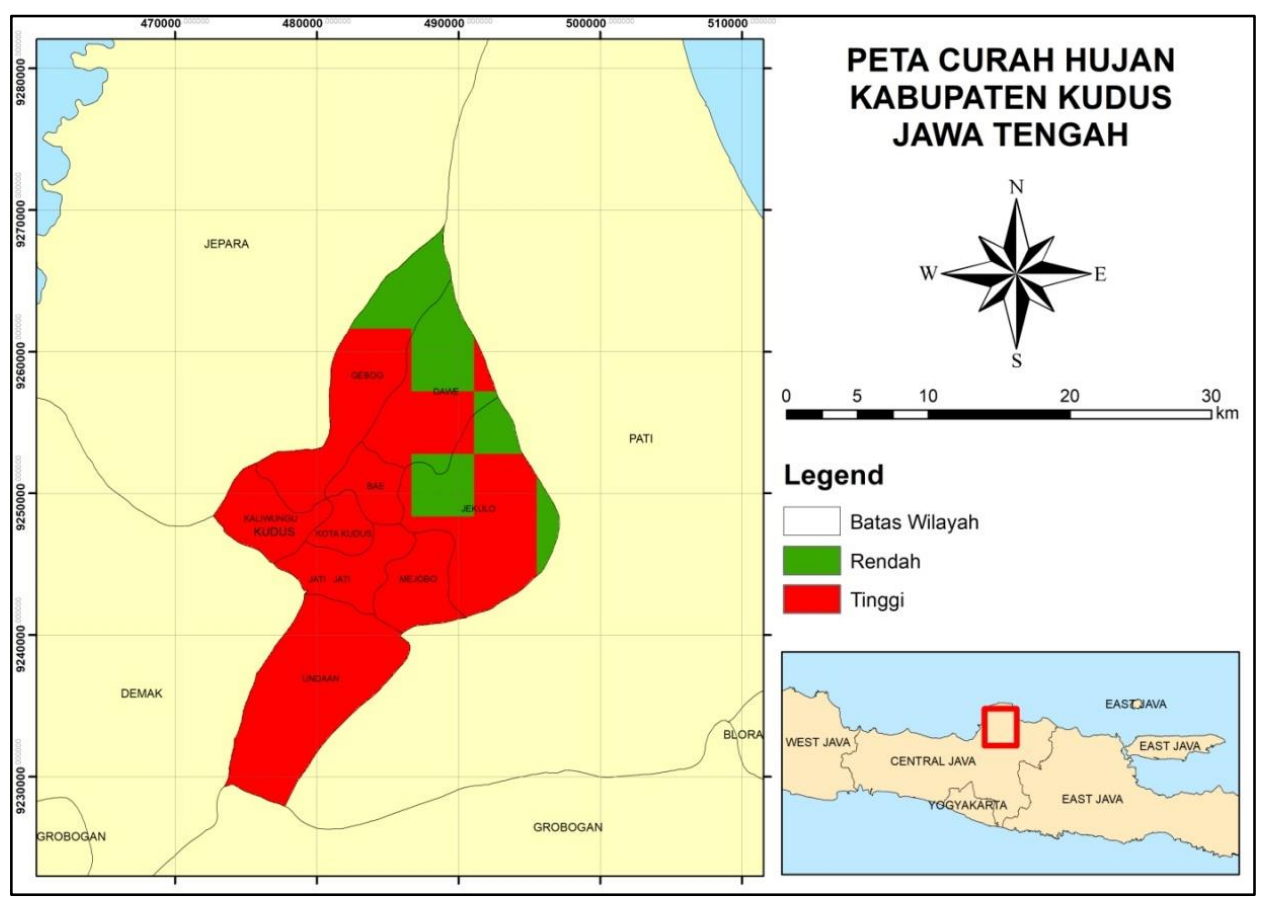

Gambar 4. Peta Curah Hujan Kabupaten Kudus Jawa Tengah

\subsection{Pembuatan Peta Jenis Tanah}

Jenis tanah berpotensi menimbulkan longsor dengan melihat tingkat kematangan tanah pada wilayah. Pembuatan peta jenis tanah di dapat menggunakan data geologi seperti pada Gambar 5 di bawah ini.

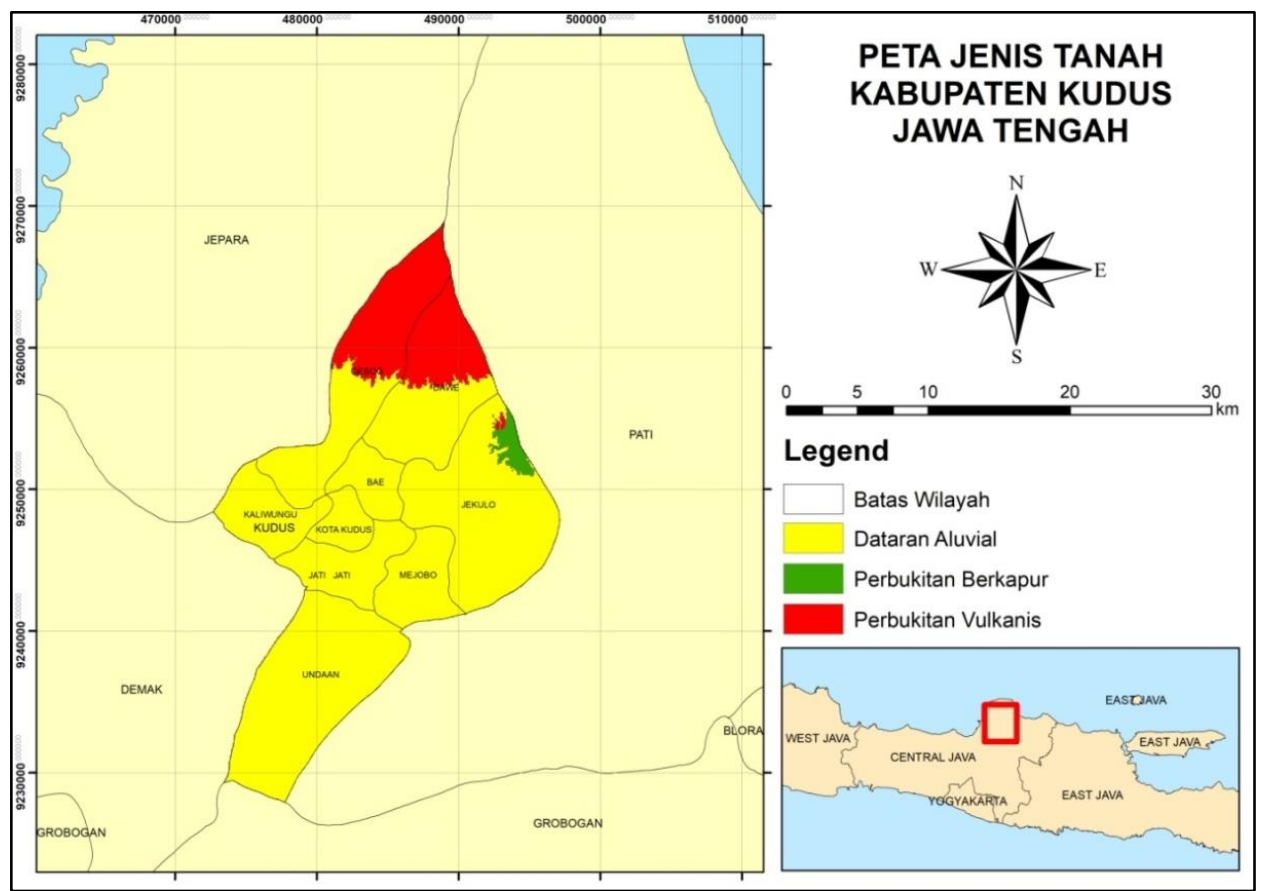

Gambar 5. Peta Jenis Tanah Kabupaten Kudus Jawa Tengah 


\subsection{Pembuatan Peta Tutupan Lahan}

Tutupan lahan memiliki konteks yang mengarah pada karakteristik penggunaan lahan. Tutupan lahan berpotensi menimbulkan longsor dengan melihat sebaran tingkat vegetasi yang ada. Pembuatan peta tata guna lahan didapatkan dari situs Indonesia Geospasial Portal yang ditunjukkan pada Gambar 6 di bawah ini.

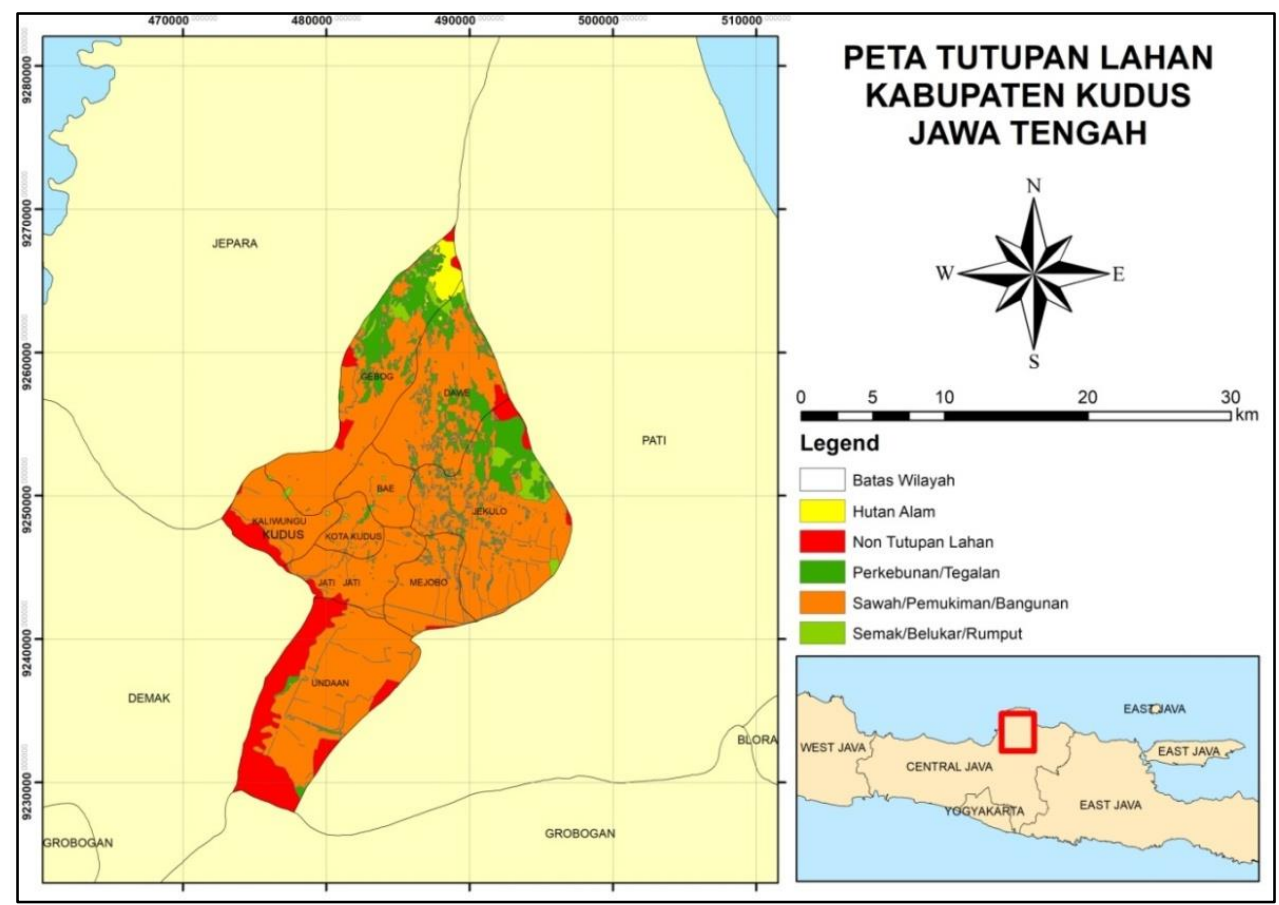

Gambar 6. Peta Tutupan Lahan Kabupaten Kudus Jawa Tengah

\subsection{Pembuatan Peta Infrastruktur}

Data infrastruktur merupakan data yang berpengaruh terhadap beban yang ada pada tanah. Semakin banyak bangunan atau infrastruktur yang ada pada wilayah maka akan semakin tinggi beban yang terdapat pada tanah dan akan mempengaruhi ketahanan tanah terhadap beban di atasnya. Semakin besar beban yang ada akan mempengaruhi tingkat rawan longsor yang semakin tinggi seperti yang ditunjukkan pada Gambar 7 .



Gambar 7. Peta Infrastruktur Kabupaten Kudus Jawa Tengah

\subsection{Pembuatan Peta Struktur Geologi}

Data struktur geologi berperan sebagai penggambaran rekahan atau patahan yang terdapat pada wilayah. Semakin banyak patahan atau rekahan pada wilayah maka akan semakin meningkatkan resiko longsor (Gambar 8). 


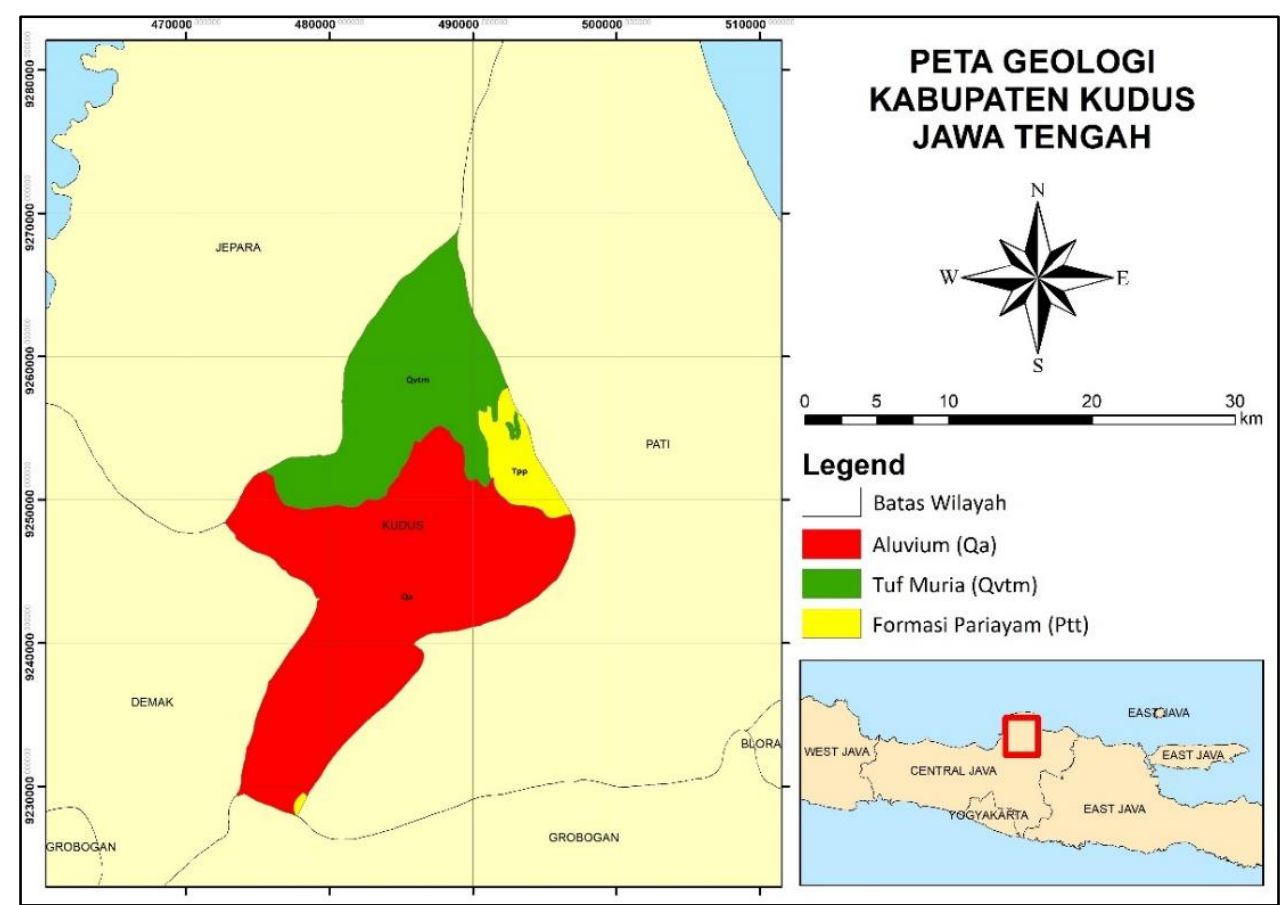

Gambar 8. Peta Geologi Kabupaten Kudus Jawa Tengah

\section{HASIL DAN PEMBAHASAN}

Pendugaan kawasan bencana zona rawan bencana tanah longsor dilakukan dengan menggunakan model pendugaan yang bersumber pada penelitian yang dilakukan oleh Puslittanak tahun 2004. Berdasarkan model tersebut parameter yang dibuat untuk menduga kawasan rawan longsor meliputi parameter jenis tanah, penutupan lahan, jenis batuan, curah hujan, serta kemiringan lahan. Semua parameter tersebut diklasifikasikan berdasarkan nilai skor kemudian diberikan bobot sesuai kontribusinya masing-masing dan kemudian data tersebut diolah. Berdasarkan hasil analisis lima parameter kerawanan longsor dengan menggunakan model Pendugaan Kerawanan Longsor Puslittanak tahun 2004, didapatkan empat kriteria wilayah kerawanan longsor yaitu daerah dengan potensi rendah, sedang, tinggi, dan sangat tinggi seperti yang ditunjukkan pada Gambar 9 di bawah ini.

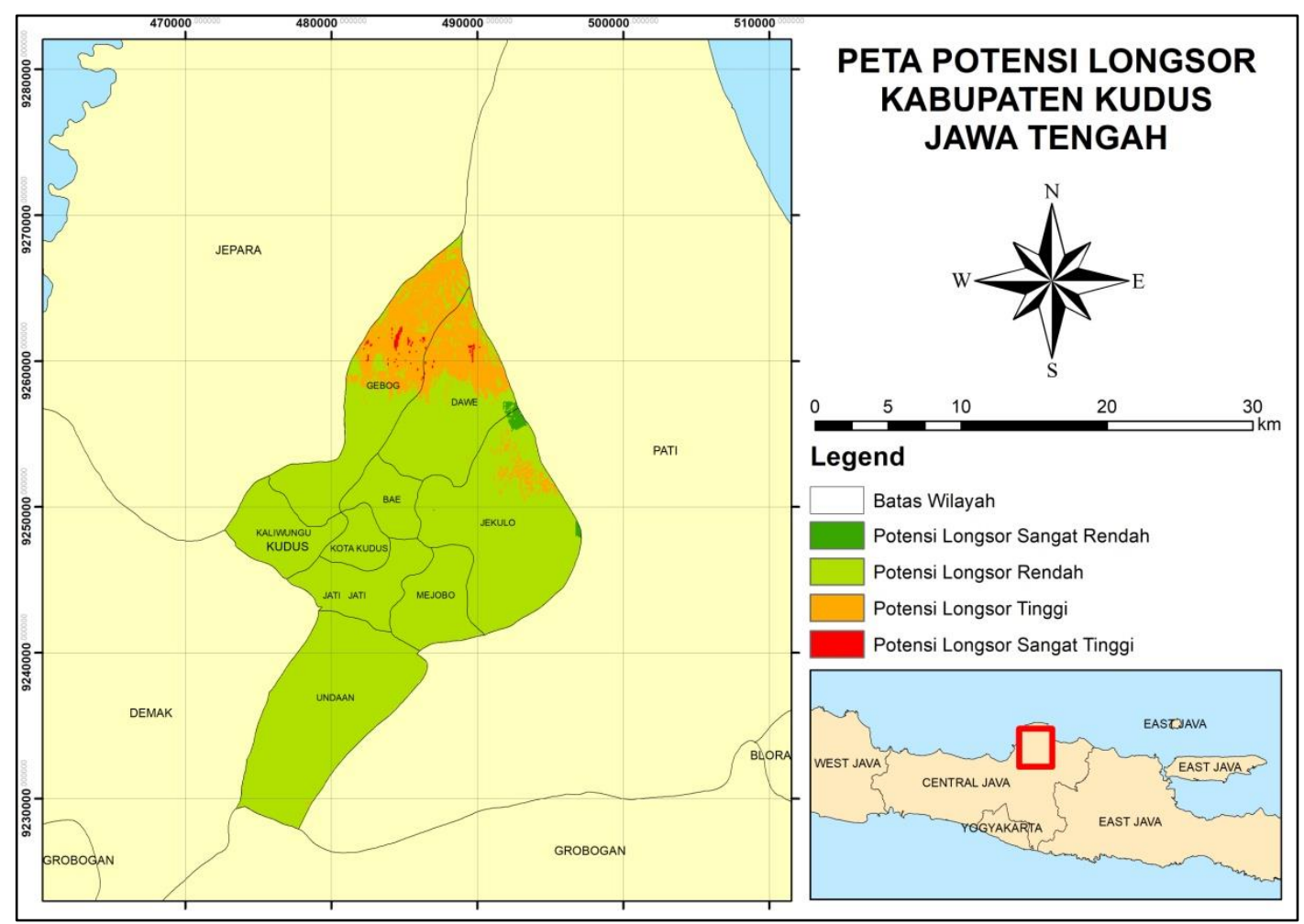

Gambar 9. Peta Potensi Longsor Kabupaten Kudus Jawa Tengah 
Berdasarkan peta potensi bencana tanah longsor di Kabupaten Kudus Jawa Tengah tersebut, diketahui bahwa wilayah penelitian ini memiliki kemungkinan terjadinya tanah longsor yang didominasi oleh tingkat potensi longsor rendah adalah Kecamatan Bae, Kaliwungu, Kota Kudus, Jati Mejobo, dan Kecamatan Undaan. Sedangkan wilayah tingkat longsor tinggi pada Kabupaten Kudus adalah sebagian Kecamatan Jekulo, Kecamatan Dewe dan Kecamatan Gebog.

\section{KESIMPULAN}

Potensi bencana tanah longsor di kabupaten kudus ini terbagi menjadi 4 kelas yaitu sangat rendah, rendah, tinggi dan sangat tinggi. Wilayahwilayah memiliki tingkat kerawanan longsor sebagai berikut: wilayah tingkat potensi longsor rendah adalah Kecamatan Bae, Kaliwungu, Kota Kudus, Jati Mejobo, dan Kecamatan Undaan. Sedangkan wilayah tingkat longsor tinggi pada Kabupaten Kudus adalah sebagian Kecamatan Jekulo, Kecamatan Dewe dan Kecamatan Gebog. Dengan adanya SIG sebagai media untuk mempermudah penyajian informasi spasial sebagai dasar interpretasi daerah potensi bencana longsor.

\section{UCAPAN TERIMA KASIH}

Puji syukur kami panjatkan kehadirat Tuhan Yang Maha Esa. Karena berkat rahmat dan hidayahnya kami dapat menyelesaikan penelitian ini. Serta terima kasih kepada seluruh pihak terkait yang membantu dalam penulisan dan pengolahan data penelitian ini, sehingga penelitian ini dapat selesai dengan baik dan diharapkan dapat bermanfaat dan digunakan dengan sebaik mungkin, sebagai pertimbangan untuk penelitian yang lebih lanjut.

\section{DAFTAR PUSTAKA}

Adininggar, F. W., Suprayogi, A., dan Wijaya, A. P. (2016). Pembuatan Peta Potensi Lahan Berdasarkan Kondisi Fisik Lahan
Menggunakan Metode Weighted Overlay. Jurnal Geodesi Undip, 5(2), 136-146.

Bahrudin, M. J. U. H. (2019). Zonasi Daerah Rawan Longsor Menggunakan Analisis Sistem Informasi Geografis Berdasarkan Metode AHP Pada Daerah Gunung Kidul Yogyakarta. Indonesian Journal of Business Intelligence (IJUBI), 1(1), 1-8.

Buchori, I., \& Susilo, J. (2012). Model Keruangan untuk Identifikasi Kawasan Rawan Longsor. Tata Loka 14(4), 282-294.

Chandra, R. K., \& Rima D. S. (2013). Mitigasi Bencana Banjir Rob di Jakarta Utara. Institut Teknologi Sepuluh November, Surabaya.

Damanik, M. R. S., \& Restu, R. (2012). Pemetaan Tingkat Risiko Banjir dan Longsor Sumatera Utara Berbasis Sistem Informasi Geografis. Jurnal Geografi, 4(1), 29-42.

Ramadhan, T. E., Suprayogi, A., \& Nugraha, A. L. (2017). Pemodelan Potensi Bencana Tanah Longsor Menggunakan Analisis SIG Di Kabupaten Semarang. Jurnal Geodesi Undip, 6(1), 118-127.

Rezainy, A. (2011). Pemanfaatan Digital Elevation Model (DEM) dan Citra ALOS AVNIR-2 Untuk Pemodelan Longsor (Studi Kasus DAS Ciliwung Hulu). Skripsi. Institut Pertanian Bogor.

Sofyan, I., Rommie J., \& Yusni, I. S. (2010). Aplikasi Sistem Informasi Geografis Dalam Penentuan Kesesuaian Kawasan Keramba Jaring Tancap Dan Rumput Laut Di Perairan Pulau Bunguran Kabupaten Natuna. Jurnal Perikanan dan Kelautan, 15(20), 111-120.

Suryana, H. E. P. (2014). Geologi Dan Analisa Resiko Bencana Longsor Daerah Menawan Dan Sekitarnya, Kecamatan Gebog, Kabupaten Kudus, Provinsi Jawa Tengah. Masters thesis, UPN "Veteran" Yogyakarta.

Van Bemmelen, R. W. (1949). The Geology of Indonesia, Vol. IA: General Geology of Indonesia and Adjacent Archipelagoes. The Hague, Martinus Nijhoff, vol. 1A, Netherlands. 